Tropical Journal of Pharmaceutical Research December 2017; 18 (4): 809-816

ISSN: 1596-5996 (print); 1596-9827 (electronic)

(1) Pharmacotherapy Group, Faculty of Pharmacy, University of Benin, Benin City, 300001 Nigeria.

\title{
Determination of sun protection factor and physical remanence of dermocosmetic emulgels formulated with Manilkara zapota (L.) fruit extract
}

\author{
Muhammad Kashif ${ }^{\star}$, Naveed Akhtar \\ Department of Pharmacy, Faculty of Pharmacy and Alternative Medicines, The Islamia University of Bahawalpur 63100, \\ Punjab, Pakistan \\ *For correspondence: Email: kashif_pharmd@yahoo.com; Tel: +92-3336362 023
}

Sent for review: 28 November 2018

Revised accepted: 19 April 2019

\begin{abstract}
Purpose: To develop a stable emulgel formulation from Manilkara zapota fruit extract (MZFE) and evaluate its sun-protective factor (SPF) and its physical retention on facial skin.

Methods: Active test formulations containing MZFE and placebo (containing no active ingredients) were prepared by dispersing the primary emulsion into a gel phase. Both test and placebo emulgel formulations were subjected to physicochemical evaluation, stability studies, and assessment of possible photo-protective properties. The sun-protective factor (SPF) was determined in vitro by spectrophotometric analysis. Non-invasive in vivo skin bioengineering technique was used to assess the UV-quenching effects of the test and placebo emulgel formulations.

Results: A stable and cosmetically acceptable emulgel formulation loaded with MZFE was obtained. The formulation and control exhibited optimum physicochemical stability in stress stability tests. The formulation exhibited promising photo-protective effects both in vitro $(S P F=14.215 \pm 0.140)$ and in vivo (lasted for approximately $120 \mathrm{~min}$ ).

Conclusion: The developed MZFE-loaded test emulgel formulation possesses suitable photoprotection capability in vitro, and displays quenching effects against specific wavelengths of UV light, indicating a UV-filtering property.
\end{abstract}

Keywords: Manilkara zapota, Emulgel, Stability testing, Photo-protection, Sun Protection Factor

\begin{abstract}
This is an Open Access article that uses a fund-ing model which does not charge readers or their institutions for access and distributed under the terms of the Creative Commons Attribution License (http://creativecommons.org/licenses/by/4.0) and the Budapest Open Access Initiative (http://www.budapestopenaccessinitiative.org/read), which permit unrestricted use, distribution, and reproduction in any medium, provided the original work is properly credited.
\end{abstract}

Tropical Journal of Pharmaceutical Research is indexed by Science Citation Index (SciSearch), Scopus, International Pharmaceutical Abstract, Chemical Abstracts, Embase, Index Copernicus, EBSCO, African Index Medicus, JournalSeek, Journal Citation Reports/Science Edition, Directory of Open Access Journals (DOAJ), African Journal Online, Bioline International, Open-J-Gate and Pharmacy Abstracts

\section{INTRODUCTION}

Excessive exposure to ultraviolet $A$ (UVA) and ultraviolet $B$ (UVB) radiations may lead to sun burn, photo aging, erythema, inflammation, hyperpigmentation disorders, wrinkle formation and immunosuppression. The UV radiations (UVR) facilitate production of reactive oxygen species (ROS) which oxidize vital bio-molecules, thereby inducing oxidative stress. The physiological antioxidant defense system is used to neutralize the deleterious effects of oxidative stress. However, because of over-exposure to UVR, oxidative stress overwhelms the cutaneous antioxidant capacity, resulting in various skin abnormalities [1]. Various synthetic sunscreen agents such as octylmethoxycinnamate, benzophenone-3 (oxybenzone), mexenone, 
provatene and avobenzone have been developed and are widely used. However, the use of these agents produces certain adverse effects such as allergic response, irritant dermatitis, hypersensitivity and melanoma [2]. These undesirable side effects may limit their acceptability. Exposure to UVR may lead to skin carcinomas and melanomas which can be prevented by avoiding UV exposure. Sunscreen products are used to abate UV exposure when applied topically.

A natural sunscreen with an added protection against UVA radiation can help prevent cutaneous photo-carcinogenesis, with lesser side effects, when compared to synthetic sunscreens. Moreover, relatively liberal amounts can be applied repeatedly as part of an effective photoprotection strategy. The quenching effect of some sunscreen formulations has been studied previously using specific UVA-emitting sources coupled with CCD cameras such as Visiopor PP34N and Visioscan VC98 (Courage + Khazaka Electronics, Germany) with promising results [3-5]. Bioactive phytoconstituents are utilized as cosmetic ingredients in many topical formulations because of their antioxidant properties. They help to capture free radicals and ROS produced by UVR, a property which gives them the potential to prevent skin aging process [6,7]. Fruits obtained from Manilkara zapota L. (family sapotaceae), commonly known as cheeku, sapota, sapodilla, ciku or naseberry, are rich in many beneficial phytoconstituents, and are widely used in folk medicines for management of cold, cough, diarrhea, pulmonary symptoms, kidney and bladder stones. Studies have shown that Manilkara Zapota fruits possess antioxidant, antimicrobial, antifungal, anticancer, antitumor, acaricidal, insecticidal, antihypertensive, anti-hyerlipidemic, antidiarrheal, anti-inflammatory, nociceptive, anticollagenase, anti-elastase and anxiolytic activities [8-13].

The present study was aimed at developing a stable cosmetic emulgel loaded with botanical extract from Manilkara zapota fruits. In addition, the UVA-filtering tendency/in vitro SPF, and UVB-quenching ability of the developed active test emulgel were determined using spectrophotometric technique and non-invasive in vivo evaluation technique, respectively.

\section{EXPERIMENTAL}

\section{Materials}

Span-80, Tween-80, Carbopol-940, ethanol, hydrochloric acid, and chloroform were purchased from Merck, Germany. Triethanolamine, methylparaben, ammonium hydroxide and sulphuric acid were obtained from Sigma-Aldrich. Mineral oil was purchased from BDH Laboratories, England.

\section{Extraction technique}

Manilkara zapota $L$ fruits were identified by Dr M Sarwar (taxonomist), Department of Life Sciences. A voucher specimen of the fruit was deposited at the herbarium of The Islamia University of Bahawalpur, Pakistan (herbarium no. 2318). The fruits were sliced into 4 pieces, and the seeds were removed. The sliced fruits were shade-dried for 4 weeks and then milled to powder. The powdered material (500 g) was soaked in $750 \mathrm{ml}$ of $70 \%$ ethanol and left to stand for $24 \mathrm{~h}$, with occasional shaking. Coarse filtration with muslin cloth was followed by fine filtration using Whatman No. 1 filter paper. The filtrate was evaporated under reduced pressure to remove about $80 \%$ of excess solvent. The sample was then placed in an oven at $50{ }^{\circ} \mathrm{C}$ to obtain a dried mass which was stored in a refrigerator prior to use.

\section{2, 2-Diphenyl-1-picryl hydrazyl (DPPH) radical scavenging assay}

Antioxidants donate electrons to DPPH radicals, thereby reducing them. The solution color fades off based on number of electron taken up by free radicals. The change in color from purple to yellow is estimated by measuring reduction in absorbance at $517 \mathrm{~nm}$. The DPPH radical scavenging activity was determined using a previously described method, but with some modifications [14]. Ninety microliters $(90 \mu \mathrm{L})$ of $100 \mu \mathrm{M}$ DPPH solution prepared in methanol was added to $10 \mu \mathrm{L}$ of test sample to make a final volume of $100 \mu \mathrm{L}$ in a 96-well microliter plate. The negative control used in this experiment was $10 \mu \mathrm{L}$ of methanol in $90 \mu \mathrm{L}$ of DPPH solution in one well. The reaction mixture was incubated at $37^{\circ} \mathrm{C}$ for $30 \mathrm{~min}$. Decrease in absorbance was measured in an ELISA microplate reader (Synergy-HT, BioTek, USA) at $517 \mathrm{~nm}$. Ascorbic acid was used as a standard. The assay was carried out in triplicate, and inhibition $(\mathrm{H})$ was calculated using Eq 1.

$H(\%)=\left\{\left(A_{0}-A_{1}\right) / A_{0}\right\} 100 \ldots \ldots \ldots$ (1)

where $A_{0}=$ absorbance of control and $A_{1}=$ absorbance of MZFE

\section{Preparation of emulgels}

A total of 25 trial emulgel formulations were 
prepared (F-1 to $\mathrm{F} 25)$ using various concentrations of surfactant, oil phase and gelling agents. These trial formulations were kept at $50{ }^{\circ} \mathrm{C}$ in stability chambers (Sanyo, Japan), for evaluation of their physicochemical stability. Stable formulations were selected for further analysis based on physicochemical and organoleptic attributes. The emulgel was prepared following two separate steps including preparation of primary emulsion (step 1). In step 2, the primary emulsion was dispersed into the prepared gel (Table 1). The oil phase and aqueous phase were heated to 70 - $80{ }^{\circ} \mathrm{C}$ in separate beakers. Then, the oily phase was added gradually into the aqueous phase at the same temperature using a lab homogenizer. Methylparaben was dissolved in small amount of propylene glycol before it was added to the aqueous phase.

Table 1: Composition of MZFE cosmetic emulgel and base

\begin{tabular}{llll}
\hline $\begin{array}{l}\text { Ingredient (\% } \\
\text { w/w) }\end{array}$ & Formulation & Base & Comment \\
\hline Liquid paraffin & 15.0 & 15.0 & Oil phase \\
Span 80 & 0.84 & 0.84 & \\
\hline Tween 80 & 2.16 & 2.16 & \\
Methylparaben & 0.05 & 0.05 & Aqueous \\
MZFE & 10.0 & 0.00 & phase \\
Water (q.s) & 100 & 100 & \\
\hline Carbopol 940 & 1.0 & 1.0 & Gel phase \\
Water (q.s) & 100 & 100 & \\
\hline
\end{tabular}

Carbopol 940 (1.0 g) was dispersed gradually into deionized water using a lab homogenizer (Eurostar, IKA, Staufen, Germany). It was sprinkled slowly to avoid any lump formation. The gel was left at room temperature for $24 \mathrm{~h}$ for completeness of carbopol hydration. Thereafter, the $\mathrm{pH}$ was adjusted to $5.5-6.5$ by dropwise addition of triethanolamine. Finally, the primary emulsion prepared in step 1 was dispersed into the gel phase with continuous stirring to obtain the emulgel.

\section{Stability studies}

Cosmetic emulgels formulation loaded with MZFE and placebo were subjected to stress stability test by placing them at temperatures of $8 \pm 0.1{ }^{\circ} \mathrm{C}$ (in a refrigerator), $25 \pm 0.1{ }^{\circ} \mathrm{C}$ (in an incubator), $40 \pm 0.1^{\circ} \mathrm{C}$ (in an incubator), and $40 \pm 0.1{ }^{\circ} \mathrm{C}$ with relative humidity $(\mathrm{RH})$ of $75 \pm 2 \%$ for a period of 90 days. During this period, changes in color, $\mathrm{pH}$ and electrical conductivity, as well as phase-separation and liquefaction were recorded. Approximately $5.0 \mathrm{~g}$ of sample was placed in a stoppered tube and centrifuged (EBA 20, Hettich, Germany) at $5000 \mathrm{rpm}$ for 10 min at $25{ }^{\circ} \mathrm{C}$ for 2 consecutive cycles. At the end of each cycle, the tube was inspected macroscopically for any possible phase separation. Electrical conductivity and $\mathrm{pH}$ were determined using digital conductivity meter (WTW, Inolab cond-7110, Germany) and $\mathrm{pH}$ meter (WTW, Inolab pH7110, Germany), respectively. Results were expressed as mean percent change in respective parameter over particular storage condition. All measurements were performed in triplicate.

\section{Ethical issues}

This study was approved by Institutional Ethical Committee (IEC), Faculty of Pharmacy and Alternative Medicines, and Board of Advanced Studies and Research of The Islamia University of Bahawalpur, Pakistan (approval no. 19/AS\&RB)., and was performed according to the guidelines of Declaration of Helsinki [15].

\section{Skin irritancy (patch) test}

Initial skin irritancy (patch) test was performed to establish the safety of the formulation for use on human volunteers by applying approximately 0.5 $\mathrm{g}$ of samples on pre-marked $(5 \mathrm{~cm} \times 4 \mathrm{~cm})$ hairfree forearm area, and covering with surgical dressing for $48 \mathrm{~h}$. Thereafter, residues of the applied samples were washed off with saline water. Increase in skin erythema level was measured using Mexameter (MPA-5, Courage + Khazaka, Germany). Visual inspection was performed for presence of redness at the site of application. Volunteers were asked if they experienced irritation during the test. Paired sample $t$-test was applied to establish statistical difference between erythema levels of MZFEloaded active test formulation and placebo at $5 \%$ level of significance $(p=0.05)$ using SPSS ver.17.0.

\section{Assessment of sun-protection factor}

Crude extract, placebo and MZFE-loaded active test formulation were subjected to spectrophotometric analysis (UV4000, ORI, Germany) for determination of SPF using in vitro method described by Napagoda et al [1], followed by application of Mansur equation [16] (equation 2). The wavelength of maximum absorption of crude extract was obtained by scanning a $1 \mathrm{mg} / \mathrm{mL}$ solution of the extract over a wavelength range of $190-400 \mathrm{~nm}$. Samples were prepared at a concentration of $1 \mathrm{mg} / \mathrm{mL}$ in ethanol, and absorbance was read between 290 
and $320 \mathrm{~nm}$ (wavelength for erythema effect spectrum) at stepwise increment of $5 \mathrm{~nm}$ [17].

$S P F=C F \times \sum_{320}^{290} E E(0) \times I(0) \times A b s(0)$

where EE $(\lambda)$ is the erythema effect spectrum; I $(\lambda)$ is solar intensity spectrum; Abs $(\lambda)$ is the absorbance of sunscreen product (test sample), and CF is correction factor $(=10)$.

Values for $E E \times$ I were constant and were calculated according to the method of Sayre et al [18] as given in Table 2. It is evident from Table 2 that if a sunscreen product transmits all of the erythemic light, it will have an SPF of 1.0, but if it absorbs all the erythemic light, it will have an infinite SPF value.

\section{Evaluation of UVA quenching tendency and physical remanence on skin}

Base and test formulation loaded with MZFE were applied using a single blinded split face study design. A total of 13 participants were enrolled after signing written informed consent. Images were captured using Visiopor PP34N CCD camera at 30 min intervals after application of test and control formulation for $5 \mathrm{~h}$ [3]. Contact of the application area with fabric and/or towel was avoided. Photographic images were analyzed using computer-based software provided with Visiopor PP34N to characterize formulation-quenching effect against UV radiations mediated by fading the follicular fluorescence dots (FFDs). The results were expressed as mean reduction in number, size and intensity of porphyrin as depicted by Visiopor ${ }^{\circledR}$ software before and after application of base and MZFE-loaded active test formulation.

\section{RESULTS}

\section{Phytochemical profile and anti-oxidant activity}

Qualitative analysis of crude extract revealed the presence of alkaloids, saponins, terpenoids, flavonoids, tannins, leukoanthocynidins, anthraquinones, glycoside, proteins, reducing sugars and carbohydrates. The free radical scavenging activity of crude ethanolic extract obtained from fruits of $M$. zapota was $82 \pm 1.03$ $\%$. Total phenolic contents of crude extract was $173 \pm 1.23 \mathrm{mg} \mathrm{GAE} / 100 \mathrm{~g}$ of dry matter. The total flavonoid contents of the crude extract was $46 \pm 1.03 \mathrm{mg} \mathrm{CE} / 100 \mathrm{~g}$ of dry matter. The yield of crude extract was $17.02 \%$.

\section{Stress stability studies}

Both base and MZFE-loaded active test formulation showed encouraging stability profiles due to absence of phase separation, color changes, odor/smell, and liquefaction within 3 months. The $\mathrm{pH}$ values of base and formulation were $5.8-6.3$ and $6.0-6.2$, respectively. The mean changes in $\mathrm{pH}$ and electrical conductivity values for base and formulation are shown in Figure 1 . Electrical conductivity ranged from 250 to $267 \mu \mathrm{S} / \mathrm{cm}$ for formulation, and from 238 to $263 \mu \mathrm{S} / \mathrm{cm}$ for base.

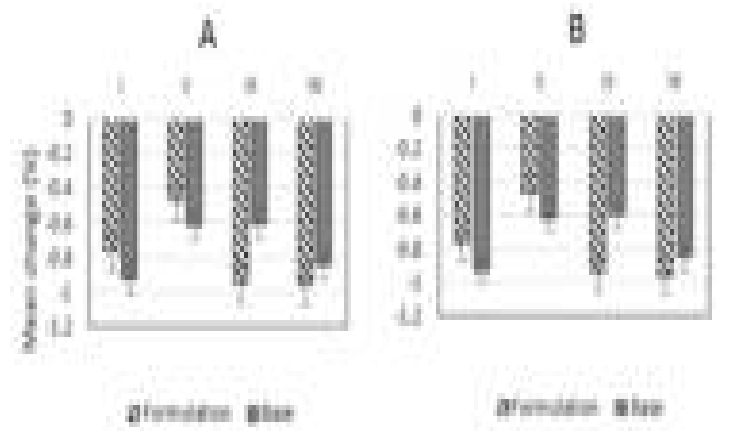

Figure 1: Mean change (\%) in ph (a) and electrical conductivity (b) for test formulation and base kept at various storage conditions for a period of 90 days

\section{Skin irritancy}

The patch test revealed that erythema levels were appreciably lower with formulation than with base. In addition, the base reduced the erythema levels at the site of application, probably due to its occlusive and hydration effects. The average percent change ( \pm SEM) observed for base and formulation after $48 \mathrm{~h}$ of application were $-0.82 \pm$ $1.70 \%$ and $-2.04 \pm 3.94 \%$, respectively (Figure 2).

Paired sample $t$-test indicated that the base and formulation exhibited insignificant effects $(p \leq$ $0.05)$ on skin erythema levels.

Table 2: Normalized product function used in calculation of SPF values

\begin{tabular}{llllllll}
\hline Wavelength $(\lambda \mathrm{nm})$ & 290.00 & 295.00 & 300.00 & 305.00 & 310.00 & 315.00 & 320.00 \\
\hline EE x I (normalized) & 0.015 & 0.0817 & 0.2874 & 0.3278 & 0.1864 & 0.0839 & 0.018 \\
\hline
\end{tabular}




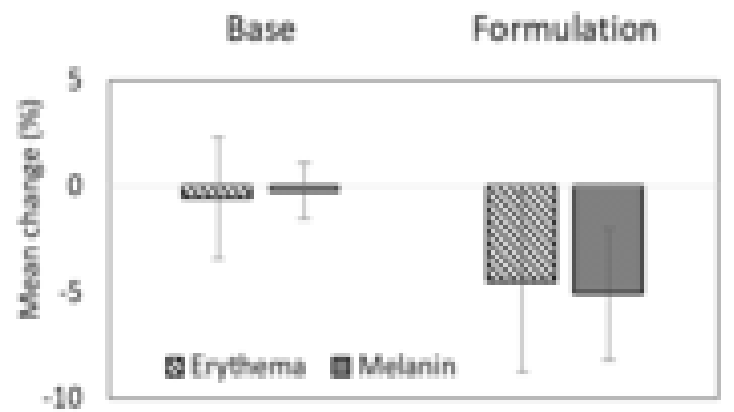

Figure 2: Mean change in erythema and melanin contents after 48 hours of application of base and test formulation

\section{UVB-filtering potential}

The antioxidant-rich extract from sapodilla fruits showed high absorption in wavelength range of $200-300 \mathrm{~nm}$ (mostly in the UVB region) with maximum peaks at 291, 227 and $215 \mathrm{~nm}$. The crude extract being rich in various antioxidants, had the highest SPF value $(22.058 \pm 0.096)$, followed by MZFE-loaded emulgel (14.215 \pm 0.140 ). Interestingly, the base formulation also showed some sort of UV filtering tendency (5.506 \pm 0.048 ) which may be due to its constituents such as liquid paraffin and gelling agent.

\section{UVA-quenching tendency and physical remanence}

Images captured at various time intervals after application of MZFE-loaded active test formulation are shown in Figure 3 . It is evident that immediately after the application, porphyrins and FFDs become invisible, indicating UVAblocking tendency of the MZFE-loaded test formulation. The filtering tendency of the prepared active test formulation lasted for 120 to 180 min (Figure 4), and then gradually faded away. However, in the case of control formulation (without MZFE), the FFDs disappeared initially, but became visible again within $30 \mathrm{~min}$. Such short duration of UV quenching ability of control formulation may be attributed to its constituents such as liquid paraffin and carbopol 940. The porphyrin size, count and average porphyrin intensity seen before and after application of base and MZFE-loaded test formulation are presented in Table 3.

\section{DISCUSSION}

Manilkara zapota fruit extract (MZFE) contains polyphenols which may contribute to its promising antioxidant activity similar to previously reported activities $[19,20]$. The $\mathrm{pH}$ values were in optimum range for their suitability as cosmetic preparations without any potential for skin irritation upon application [21,22]. There was a slight downward shift in $\mathrm{pH}$ values for both base and formulation which may be due to oxidation of fats at accelerated storage conditions. There were slight reductions in electrical conductivities of base and formulation under various storage conditions with passage of time.

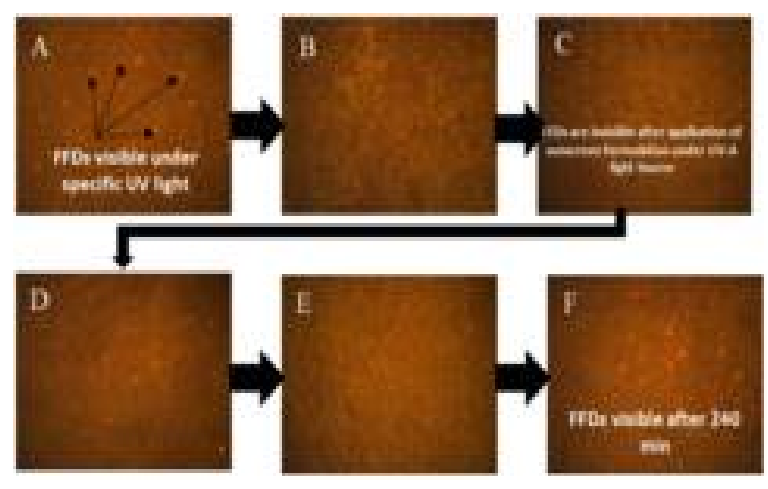

Figure 3: Visiopor PP34N: Follicular fluorescing dots and porphyrins under Visiopor camera after application of formulation: $\mathrm{A}=$ before application; $\mathrm{B}=$ immediately after application; $C=30 \mathrm{~min}$ after application; $D=60 \mathrm{~min}$ after application; $\mathrm{E}=90 \mathrm{~min}$ after application, and $\mathrm{F}=\mathbf{2 4 0} \mathrm{min}$ after application

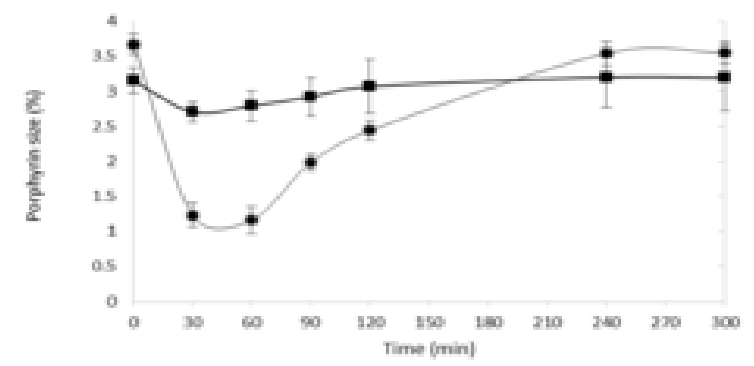

Figure 4: Mean change in porphyrin size (\%) before and after application of formulation and base at 30-min intervals. Base: a; MZFE-loaded formulation: •

However, the change was relatively more prominent in samples kept at $40{ }^{\circ} \mathrm{C}$, indicating that dry heat (without $75 \% \mathrm{RH}$ ) was a major factor contributing towards changes in $\mathrm{pH}$ and conductivity in base and formulation. It can be argued that MZFE did not significantly alter the $\mathrm{pH}$ and electrical conductivity of the prepared emulgels. All volunteers enrolled in the study showed no redness on visual inspection of the site of application after $48 \mathrm{~h}$.

Both base and test formulation did not produce any erythema effects at the site of application. Rather, a slight reduction in both erythema and melanin contents were observed, which may be attributed to various polyphenolic constituents of the formulation. The in vitro spectrophotometric method used to determine SPF of the samples is 
Table 3: Variations in FFDs observed before and after application of base- and MZFE-loaded active test formulation

\begin{tabular}{|c|c|c|c|c|c|c|c|c|}
\hline & Time (min) & Initial value & 30 & 60 & 90 & 120 & 240 & 300 \\
\hline \multirow{3}{*}{ 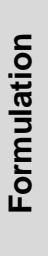 } & Porphyrins size (\%) & $3.54 \pm 1.50$ & $0.93 \pm 0.44$ & $1.37 \pm 0.67$ & $2.04 \pm .84$ & $3.06 \pm 1.18$ & $3.32 \pm 1.32$ & $3.52 \pm 1.45$ \\
\hline & Porphyrins count & $62 \pm 16.40$ & $20 \pm 4.45$ & $28 \pm 6.86$ & $36 \pm 7.88$ & $54 \pm 13.44$ & $60 \pm 15.89$ & $66 \pm 18.54$ \\
\hline & Porphyrins avg. intensity & $205 \pm 24.58$ & $119 \pm 22.21$ & $140 \pm 15.01$ & $167 \pm 5.96$ & $198 \pm 20.54$ & $209 \pm 23.46$ & $217 \pm 24.21$ \\
\hline \multirow{3}{*}{ 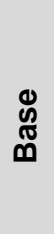 } & Porphyrins size (\%) & $3.94 \pm 0.92$ & $3.38 \pm 0.77$ & $3.49 \pm 0.80$ & $3.65 \pm 0.86$ & $3.84 \pm 0.93$ & $4.00 \pm 1.05$ & $3.99 \pm 0.94$ \\
\hline & Porphyrins ount & $60 \pm 16.63$ & $48 \pm 13.72$ & $51 \pm 14.84$ & $56 \pm 14.52$ & $58 \pm 14.81$ & $59 \pm 15.27$ & $63 \pm 17.35$ \\
\hline & Porphyrins avg. intensity & $202 \pm 28.08$ & $175 \pm 15.82$ & $179 \pm 12.98$ & $188 \pm 16 ., 67$ & $192 \pm 22.22$ & $196 \pm 23.86$ & $200 \pm 27.40$ \\
\hline
\end{tabular}


based on UVB absorption. Thus, it does not give any indication of the UVA radiation-blocking potential of the formulation. The in vivo method used to determine the SPF gives an idea of the protection afforded by any formulation against erythema produced by a single exposure to UV radiation, with partial evidence about UVA protection. Visiopor-PP34N coupled with sixteen diode LEDs emits light in the UVA spectrum $(375-385 \mathrm{~nm})$ which activates porphyrins and other flourochromes on the skin of the face, resulting in easy visualization of follicular fluorescence dots (FFDs). These fluorescing entities can be captured by a built-in CCDcamera [4].

The fluorescence intensity of porphyrins and flourochromes can be reduced by sieving the UVA light with some UV filters. Based on this principle, the UVA-filtering potential of the formulated emulgels (base and formulation) were evaluated after topical applications by measuring alterations in the number and size of FFDs with the help of visiopor-PP34N® coupled with CCD cameras for capturing the images. The FFDs are easily seen with Visiopor ${ }^{\circledR}-\mathrm{PP} 34 \mathrm{~N}$ due to emission of UVA light in the range of $375-385$ $\mathrm{nm}[5,23-25]$. The incident light from device is reflected back and scattered near the skin surface. Such specular light reflectance (SLR) can be detected with CCD camera, although it is hardly seen with the naked eye. The observance of SLR-induced skin images is non-invasive, ethical and safe to human beings. After application of the formulation, the FFDs faded away, trailed by a progressive reappearance with passage of time. The subsidence of FFDs was more prominent and long-lasting in the formulation, relative to base. Test formulation loaded with MZFE efficiently sieved UVA light, resulting in reduction in porphyrin size, count and average intensity. The topical hindrance of FFDs, in vitro SPF and porphyrin count, and intensity reduction clearly demonstrate the UVA- and UVB-quenching effects of the prepared formulation. However, it can be safely claimed that the MZFE-loaded cosmetic emulgel formulation has relatively long duration of protection against UVA radiations as evaluated by non-invasive in vivo technique utilizing Visiopor CCD camera. The quenching effect of formulation against UVA radiation commences immediately after application and lasts for approximately $120 \mathrm{~min}$. If someone presents with skin erythema or skin redness after $20 \mathrm{~min}$ of unprotected exposure to the sun, theoretically they may stay in the sun 15 times longer (approximately $5 \mathrm{~h}$ ) after applying SPF-15 formulation. This theoretical concept is based on skin reddening because of UVB radiations.
However, sufficient damage can be done by UVA radiations to increase susceptibility to sun burn and eventually skin carcinomas. The SPF value of $14.215 \pm 0.140$ for active emulgel formulation loaded with MZFE is almost equivalent to SPF15 , indicating its potential for utilization in commercial sunscreen products. Moreover, the stable emulgel produced can efficiently be used to prevent any possible photo damage due to UVA and UVB, thereby preventing various skin conditions related to UV-exposure and photoaging.

\section{CONCLUSION}

The developed formulation and base are stable at $8,25,40$, and $40{ }^{\circ} \mathrm{C}$, and $75 \% \mathrm{RH}$. The active test formulation prepared with MZFE is nonirritant and apparently safe for human use but further toxicological tests are required. Nonetheless, the formulation has promising quenching effects against UVA and UVB radiations. These attributes make MZFE a potentially suitable ingredient for use in the formulation of cosmetic sunscreen and photoprotective formulations.

\section{DECLARATIONS}

\section{Acknowledgement}

The authors are thankful to the Department of Pharmacy and Alternative Medicines, The Islamia University of Bahawalpur, for financial and non-financial support.

\section{Conflict of Interest}

No conflict of interest associated with this work.

\section{Contribution of Authors}

The authors declare that this work was done by the authors named in this article and all liabilities pertaining to claims relating to the content of this article will be borne by them.

\section{Open Access}

This is an Open Access article that uses a funding model which does not charge readers or their institutions for access and distributed under the terms of the Creative Commons Attribution License (http://creativecommons.org/licenses/by/ 4.0) and the Budapest Open Access Initiative (http://www.budapestopenaccessinitiative.org/rea d), which permit unrestricted use, distribution, and reproduction in any medium, provided the original work is properly credited. 


\section{REFERENCES}

1. Napagoda MT, Malkanthi BM, Abayawardana SA, Qader MM, Jayasinghe L. Photoprotective potential in some medicinal plants used to treat skin diseases in Sri Lanka. BMC Complement Altern Med. 2016; 16(1): 479.

2. Chanchal $D$, Swarnlata $S$. Herbal photoprotective formulations and their evaluation. Open Nat Prod J. 2009; 2: 71.

3. Pierard GE, Khazaka D, Khazaka G. Sunscreen remanence on the skin: a noninvasive real time in vivo spectral analysis assessing the quenching of specular ultraviolet $A$ light reflectance. Journal of cosmetic dermatology. 2016; 15(1): 3-9.

4. Pierard-Franchimont C, Quatresooz P, Pierard GE. Specular light reflectance of flakes in seborrhoeic dermatitis of the scalp: a pilot study. Clinical and experimental dermatology. 2011; 36(7): 793-796.

5. Szepetiuk G, Pierard S, Pierard-Franchimont C, Caucanas M, Quatresooz P, Pierard GE. Recent trends in specular light reflectance beyond clinical fluorescence diagnosis. European Journal of Dermatology. 2011; 21(2): 157-161.

6. Akhtar N, Khan BA, Haji M, Khan S, Ahmad M, Rasool F, Mahmood T, Rasul A. Evaluation of various functional skin parameters using a topical cream of Calendula officinalis extract. African journal of Pharmacy and Pharmacology. 2011; 5(2): 199-206.

7. Rasul A, Akhtar N. Anti-aging potential of a cream containing milk thistle extract: Formulation and in vivo evaluation. African Journal of Biotechnology. 2012; 11(6): 1509-1515.

8. Osman MA, Rashid MM, Aziz MA, Habib MR, Karim MR. Inhibition of Ehrlich ascites carcinoma by Manilkara zapota L. stem bark in Swiss albino mice. Asian Pacific journal of tropical biomedicine. 2011; 1(6): 448-451.

9. Wang $H$, Liu $T$, Song L, Huang D. Profiles and alphaamylase inhibition activity of proanthocyanidins in unripe Manilkara zapota (chiku). Journal of agricultural and food chemistry. 2012; 60(12): 3098-3104.

10. Barbalho SM, Bueno PC, Delazari DS, Guiguer EL, Coqueiro DP, Araujo AC, de Souza Mda S, FarinazziMachado FM, Mendes CG, Groppo M. Antidiabetic and antilipidemic effects of Manilkara zapota. Journal of medicinal food. 2015; 18(3): 385-391.

11. Guevarra MTB, Panlasigui LN. Blood glucose responses of diabetes mellitus type II patients to some local fruits. Asia Pacific Journal of Clinical Nutrition. 2000; 9(4): 303308.

12. Fayek NM, Monem AR, Mossa MY, Meselhy MR. New triterpenoid acyl derivatives and biological study of
Manilkara zapota (L.) Van Royen fruits. Pharmacognosy research. 2013; 5(2): 55-59.

13. Fang JY, Wang PW, Huang $\mathrm{CH}$, Chen $\mathrm{MH}$, Wu YR, Pan $T L$. Skin aging caused by intrinsic or extrinsic processes characterized with functional proteomics. Proteomics. 2016; 16(20): 2718-2731.

14. Mohsin S, Akhtar N, Mahmood T, Khan H, Mustafa R. Formulation and stability of topical water in oil emulsion containing corn silk extract. Tropical Journal of Pharmaceutical Research. 2016; 15(6): 1115-1121.

15. Association WM. World Medical Association Declaration of Helsinki. Ethical principles for medical research involving human subjects. Bulletin of the World Health Organization. 2001; 79(4): 373.

16. Mansur JdS, Breder MNR, Mansur MCdA, Azulay RD. Determinaçäo do fator de proteçäo solar por espectrofotometria. An Bras Dermatol. 1986; 61(3): 121 124.

17. Dutra EA, Oliveira DAGdC, Kedor-Hackmann ERM, Santoro MIRM. Determination of sun protection factor (SPF) of sunscreens by ultraviolet spectrophotometry. Revista Brasileira de Ciências Farmacêuticas. 2004; 40(3): 381-385.

18. Sayre RM, Agin PP, LeVee GJ, Marlowe E. A comparison of in vivo and in vitro testing of sunscreening formulas. Photochemistry and Photobiology. 1979; 29(3): 559-566.

19. Gomathy K, Baskar R, Kumaresan K. Comparison of antioxidant potential in pulp and peel extracts of Manilkara zapota (L.) P. Royen. African Journal of Biotechnology. 2013; 12(31): 4936.

20. Kulkarni AP, Policegoudra R, Aradhya S. Chemical composition and antioxidant activity of sapota (Achras sapota Linn.) fruit. Journal of food biochemistry. 2007; 31(3): 399-414.

21. Lucero M, Vigo J, Leon M. A study of shear and compression deformations on hydrophilic gels of tretinoin. International journal of pharmaceutics. 1994; 106(2): 125-133.

22. Mohamed MI. Optimization of chlorphenesin emulgel formulation. The AAPS journal. 2004; 6(3): e26.

23. Richter C, Trojahn C, Dobos G, Blume-Peytavi U, Kottner J. Follicular fluorescence quantity to characterize acne severity: a validation study. Skin research and technology: official journal of International Society for Bioengineering and the Skin. 2016; 22(4): 451-459.

24. Szepetiuk G, Piérard-Franchimont C, Quatresooz P, Piérard G. How I explore... skin by photodiagnosis using skin fluorescence and its functional imaging. Revue medicale de Liege. 2010; 65(9): 521-526.

25. Szepetiuk G, Piérard-Franchimont C, Quatresooz $P$, Piérard G. Physico-biological foundation of skin fluorescence--review. Pathologie-biologie. 2012; 60(6): 380-386. 